\author{
Military Technical College \\ Kobry El-Kobbah, \\ Cairo, Egypt.
}

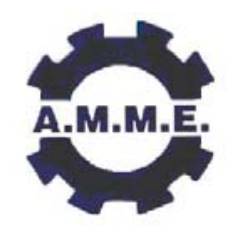

\title{
AERO-THERMO-MECHANICAL CHARACTERISTICS \\ OF SHAPE MEMORY ALLOY HYBRID COMPOSITE PANELS \\ WITH GEOMETRIC IMPERFECTION
}

\author{
IBRAHIM ${ }^{*}$ H.H. and TAWFIK ${ }^{* *} \mathrm{M}$.
}

\begin{abstract}
A new nonlinear finite element model is presented for the static aero-thermal deflection of a shape memory alloy (SMA) hybrid composite panel with initial geometric imperfection and under the combined effect of thermal and aerodynamic loads. The nonlinear governing equations are obtained using Marguerre curved plate theory and the principle of virtual work. The effect of large deflection is included in the formulation through the von Karman nonlinear strain-displacement relations. To account for the temperature dependence of material properties, the thermal strain is stated as an integral quantity of the thermal expansion coefficient with respect to temperature. The aerodynamic pressure is modeled using the quasi-steady first-order piston theory. The Newton-Raphson iteration method is employed to obtain the nonlinear aero-thermal deflections, while an Eigen value problem is solved at each temperature and static aerodynamic load to predict the free vibration frequencies about the deflected equilibrium position. Finally, the nonlinear deflection and free vibration characteristics of a SMA hybrid composite panel are presented, illustrating the effect of SMA fiber embeddings, temperature rise, dynamic pressure, boundary conditions and an initial geometric imperfection on the panel response.
\end{abstract}

\section{KEY WORDS}

Shape Memory Alloy, Fundamental Frequency, Aero-Thermal Buckling, Geometric Imperfection

\footnotetext{
* Assistant Professor, Space Division, National Authority for Remote Sensing and Space Sciences, Cairo, Egypt, hesham.ibrahim@narss.sci.eg

** Assistant Professor, Mechanical Department, British University in Egypt, Cairo, Egypt, Mohammad.Tawfik@bue.edu.eg
} 


\section{INTRODUCTION}

The external skin of high speed flight vehicles experiences high temperatures due to aerodynamic heating, which can induce thermal buckling and may results in a dynamic instability. In general, thermal buckling does not indicate structural failure. However, large thermal deflections of the skin panels can change its aerodynamic shape affecting reduction in the flight performance. A comprehensive literature review on thermally induced flexure, buckling, and vibration of plates and shells was presented by Tauchart [1] and Thornton [2]. Gray and Mei [3] investigated the thermal post-buckling behavior and free vibration of thermally buckled composite plates using the finite element method. Jones and Mazumdar [4] investigated the linear and non-linear dynamic behavior of plates at elevated temperatures. They presented analytical solutions for the thermal buckling and post-buckling behavior of a plate strip. Shi et al. [5] presented a finite element solution for the thermal buckling behavior of laminated composite plates under combined mechanical and thermal loads. Ibrahim et al. [6] investigated the thermal buckling and flutter boundaries of thin functionally graded material plates at elevated temperature. They adopted an incremental finite element technique to capture the effect of the temperature-dependence of material properties on the panel response. Ibrahim et al. [7] presented a finite element solution for the thermal buckling and nonlinear flutter performance of thin functionally graded material panels under combined aerodynamic and thermal loads. To account for the temperature-dependence of material properties, the thermal strain was modeled as an integral quantity of thermal expansion coefficient with respect to temperature. Ibrahim et al. [8] extended the formulation presented in [7] by including the shear deformation effect to make it capable of handling thick functionally graded material plates.

The initial geometric imperfections are inherent in many real structures. Therefore, many investigations are conducted on the stability analysis and free vibration of imperfect structures. Shi et al. [9] adopted a finite element modal method to solve the problem of thermal post-buckling of composite plates with initial imperfections. Shen [10] presented a thermal postbuckling analysis for simply supported imperfect shear deformable laminated plates subjected to a uniform temperature rise and resting on an elastic foundation. A perturbation technique and an iterative numerical procedure were employed to determine the buckling temperature and thermal postbuckling loaddeflection curves. Girish and Ramachandra [11] investigated the thermal postbuckling deflection and free vibration behavior of thermally buckled laminated composite plates with initial geometric imperfections. The structural model was based on a higher-order shear deformation theory, von Karman nonlinear strain-displacement relations and a multi-term Galerkin's approximation. Shariat and Eslami [12] presented a closed form solution for the critical buckling temperature change of an imperfect functionally graded plate using classical plate theory. Mirzavand and Eslami [13] presented a closed form solution for the critical buckling temperature change of functionally graded cylindrical shells using the Wan-Donnell model for initial imperfections. They utilized the first-order classical shell theory along with the Sanders nonlinear kinematic relations. Shen [14] employed a two-step perturbation technique to determine the buckling temperature and postbuckling equilibrium paths for an imperfect shear deformable FGM plate with temperature-dependent properties.

Shape memory alloys (SMA) have a unique ability to completely recover large prestrains (up to $10 \%$ elongation) when heated above certain characteristic temperature. During the shape recovery process, a large tensile recovery stress occurs if the SMA is 
restrained. Both the recovery stresses and Young's modules of SMA exhibit nonlinear temperature-dependent properties. The variation of the modulus of elasticity and recovery stress of a trained Nitinol are presented in Figure1 [15]. Birman [16] presented a comprehensive review on the literature concerning SMA up to 1997. Tawfik et al. [17] proposed a novel concept in enhancing the thermal buckling and aeroelastic behavior of plates through embedding SMA fibers in it. Park et al. [18] investigated the nonlinear vibration behavior of thermally buckled composite plates embedded with shape memory alloy fibers. An incremental method was adopted to account for the temperature dependent material properties. Ibrahim et al. [19] investigated the thermal buckling and free vibration behavior of thick, shape memory alloy hybrid composite plates. Moreover, a frequency domain solution for predicting panel flutter boundaries at elevated temperatures was presented. Ibrahim et al. [20] investigated the nonlinear random response of moderately thick composite plates impregnated with pre-strained shape memory alloy fibers under combined thermal and random acoustic loads.

This paper is an extension of the work presented in [19] and [20] by including the influence of geometrical imperfections in the formulation. In this work, a new nonlinear finite element model is presented for the aero-thermal buckling and free vibration response of an imperfect shape memory alloy hybrid composite (SMAHC) panel under combined thermal and aerodynamic loads. The nonlinear governing equations for a thin, imperfect rectangular panel are obtained using Marguerre curved plate theory, von Karman strain-displacement relations, and the principle of virtual work. To account for the temperature-dependence of material properties, the thermal strain is modeled as an integral quantity of the thermal expansion coefficient with respect to temperature [7]. Numerical results are provided to show the effect of the temperature rise, pre-strained SMA fiber embeddings, dynamic pressure and an initial geometric imperfection on the panel response.

\section{FINITE ELEMENT FORMULATION}

\section{Nonlinear Strain-Displacement Relations}

The nodal degrees of freedom vector $\{\theta\}$ of a rectangular four-noded Bogner-FoxSchmidt (BFS) $\mathrm{C}^{1}$ conforming plate element can be written as:

$$
\{\theta\}=\left\{\left\{w, \frac{\partial w}{\partial x}, \frac{\partial w}{\partial y}, \frac{\partial^{2} w}{\partial x \partial y}\right\},\{u, v\}\right\}^{T}=\left\{\begin{array}{l}
\left\{w_{b}\right\} \\
\left\{w_{m}\right\}
\end{array}\right\}
$$

where $\left\{w_{b}\right\}$ is the nodal transverse displacement and rotations vector and $\left\{w_{m}\right\}$ is the nodal membrane displacements vector. Consider the initial geometric imperfection $w_{\mathrm{o}}$ and the lateral deflection $w$ shown in Figure 2, the Marguerre curved plate straindisplacement relation along with von Karman large deflection can be written as [21]: 


$$
\left\{\begin{array}{c}
\varepsilon_{x} \\
\varepsilon_{y} \\
\gamma_{x y}
\end{array}\right\}=\left\{\begin{array}{c}
\frac{\partial u}{\partial x} \\
\frac{\partial v}{\partial y} \\
\frac{\partial u}{\partial y}+\frac{\partial v}{\partial x}
\end{array}\right\}+\left\{\begin{array}{c}
\frac{1}{2}\left(\frac{\partial w}{\partial x}\right)^{2} \\
\frac{1}{2}\left(\frac{\partial w}{\partial y}\right)^{2} \\
\frac{\partial w}{\partial x} \frac{\partial w}{\partial y}
\end{array}\right\}+\left\{\begin{array}{c}
\frac{\partial w}{\partial x} \frac{\partial w_{o}}{\partial x} \\
\frac{\partial w}{\partial y} \frac{\partial w_{o}}{\partial y} \\
\frac{\partial w}{\partial x} \frac{\partial w_{o}}{\partial y}+\frac{\partial w_{o}}{\partial x} \frac{\partial w}{\partial y}
\end{array}\right\}+z\left\{\begin{array}{c}
-\frac{\partial^{2} w}{\partial x^{2}} \\
-\frac{\partial^{2} w}{\partial y^{2}} \\
-2 \frac{\partial^{2} w}{\partial x \partial y}
\end{array}\right\}
$$

Or in a compact form as:

$\{\varepsilon\}=\left\{\varepsilon_{m}^{o}\right\}+\left\{\varepsilon_{b}^{o}\right\}+\left\{\varepsilon_{w o}^{o}\right\}+z\{\kappa\}$

$\left\{\varepsilon_{m}^{o}\right\},\left\{\varepsilon_{b}^{o}\right\},\left\{\varepsilon_{w o}^{o}\right\}$, and $z\{\kappa\}$ are the membrane linear strain vector, the membrane nonlinear strain vector, inplane strain vector due to geometric imperfection and the bending strain vector, respectively. In addition, the initial geometric imperfection is assumed to have the form:

$$
w_{o}=w^{*} \sin \frac{\pi x}{a} \sin \frac{\pi y}{b}
$$

where $a, b$ are the plate dimensions along $x$ and $y$ directions, respectively.

\section{Constitutive Equations}

For the $\mathrm{k}^{\text {th }}$ composite lamina impregnated with SMA fibers, the stress-strain relations can be expressed as [19]:

$$
\{\sigma\}^{k}=\left\{\begin{array}{l}
\sigma_{x} \\
\sigma_{y} \\
\tau_{x y}
\end{array}\right\}^{k}=[\bar{Q}(T)]^{k}\{\varepsilon\}+\left\{\sigma_{r}(T)\right\}^{k} V_{s}^{k}-V_{m}^{k} \int_{T_{r f}}^{T}[\bar{Q}(\tau)]_{m}^{k}\left\{\alpha(\tau)_{m}^{k}\right\} d \tau
$$

where $\{\sigma\}$ and $\left\{\sigma_{r}\right\}$ are the in-plane and the SMA recovery stress vectors at a given temperature $T . V_{m}$ and $V_{s}$ are the volume fractions of the composite matrix and SMA fibers, respectively. In addition, $\{\alpha\}_{\mathrm{m}},[\bar{Q}]$ and $[\bar{Q}]_{\mathrm{m}}$ are the thermal expansion coefficient vector of the composite matrix, the transformed reduced stiffness matrix of the SMA embedded lamina, and the transformed reduced stiffness matrix of the composite matrix, respectively. Note that the SMA fibres are embedded in same direction of the composite matrix fibers, and assumed uniformly distributed within each layer. Integrating Equation (5) over the plate thickness $h$, the constitutive equation is obtained as:

$$
\left\{\begin{array}{l}
\{N\} \\
\{M\}
\end{array}\right\}=\left[\begin{array}{cc}
{[A]} & {[B]} \\
{[B]} & {[D]}
\end{array}\right]\left\{\begin{array}{c}
\left\{\varepsilon_{m}^{o}\right\}+\left\{\begin{array}{c}
o \\
\varepsilon_{b}
\end{array}\right\}+\left\{\varepsilon_{w o}^{o}\right\} \\
\{\kappa\}
\end{array}\right\}-\left\{\begin{array}{c}
\left\{N^{T}\right\} \\
\left\{M^{T}\right\}
\end{array}\right\}+\left\{\begin{array}{l}
\left\{N_{r}\right\} \\
\left\{M_{r}\right\}
\end{array}\right\}
$$

where 
$\left(\left\{N^{T}\right\},\left\{M^{T}\right\}\right)=\int_{-h / 2}^{h / 2}\left[\left(\int_{T_{r e f}}^{T}[Q(\tau)]\{\alpha(\tau)\} d \tau\right)\right](1, z) d z, \quad\left(\left\{N_{r}\right\},\left\{M_{r}\right\}\right)=\int_{-h / 2}^{h / 2}\left\{\sigma_{r}\right\} V_{s}(1, z) d z$

\section{Aerodynamic Pressure Loading}

The first-order quasi-steady piston theory for supersonic flow states that [17]:

$$
P_{a}=-\left(\frac{g_{a}}{\omega_{o}} \frac{D_{110}}{a^{4}} \frac{\partial\left(w+w_{o}\right)}{\partial t}+\lambda \frac{D_{110}}{a^{3}} \frac{\partial\left(w+w_{o}\right)}{\partial x}\right)
$$

with

$$
\begin{gathered}
\lambda=\frac{2 q a^{3}}{\beta D_{110}}, \quad q=\frac{\rho_{a} v^{2}}{2}, \quad \beta=\sqrt{M_{\infty}^{2}-1}, \quad \omega_{\mathrm{o}}=\left(\frac{D_{110}}{\rho h a^{4}}\right)^{\frac{1}{2}}, \\
\mathrm{C}_{\mathrm{a}}=\frac{\left(M_{\infty}^{2}-2\right)^{2}}{\left(M_{\infty}^{2}-1\right)^{2}} \frac{\rho_{a} a}{\rho h \beta}, \quad \text { and } \quad g_{a}=\frac{\rho_{a} v\left(M_{\infty}^{2}-2\right)}{\rho h \omega_{\mathrm{o}} \beta^{3}}=\sqrt{\lambda \mathrm{C}_{\mathrm{a}}}
\end{gathered}
$$

where $P_{a}$ is the aerodynamic pressure loading, $v$ is the airflow velocity on one side of the panel, $M_{\infty}$ is the Mach number, $q$ is the dynamic pressure, $\rho_{a}$ is the air mass density, $g_{a}$ is the non-dimensional aerodynamic damping, $C_{a}$ is the aerodynamic damping coefficient, $\lambda$ is the non-dimensional dynamic pressure, $D_{110}$ is the first entry in the flexural stiffness matrix $D(1,1)$ when all the fibers of the composite layers are aligned in the airflow $x$-direction, and $a$ is the stream wise panel length.

\section{Governing Equations}

The principal of virtual work states that

$$
\delta \text { Work }=\delta \text { Work }_{\text {int }}-\delta \text { Work }_{\text {ext }}=0
$$

where the virtual work done by internal stresses can be written as:

$$
\begin{aligned}
\delta \text { Work }_{\text {int }} & =\int_{A}\left(\left\{\delta\left(\left\{\varepsilon_{m}^{o}\right\}+\left\{\varepsilon_{b}^{o}\right\}+\left\{\varepsilon_{w_{o}}^{o}\right\}\right)\right\}^{T}\{N\}+\{\delta \kappa\}^{T}\{M\}\right) d A \\
= & \{\delta \theta\}^{T}\left([k]+\left[k_{w o}\right]-\left[k_{T}\right]+\left[k_{r}\right]+\frac{1}{2}\left([n 1]+\left[n 1_{w o}\right]\right)+\frac{1}{3}[n 2]\right)\{\theta\} \\
& -\{\delta \theta\}^{T}\left(\left\{p_{T}\right\}+\left\{p_{T w o}\right\}-\left\{p_{r}\right\}-\left\{p_{r w o}\right\}\right)
\end{aligned}
$$

where $[k],\left[k_{T}\right]$ and $\left[k_{r}\right]$ are the linear, thermal and recovery stress stiffness matrices; $\left[k_{w o}\right]$ is a linear stiffness matrix due to geometric imperfection; [ $\left.n 1\right]$ and [ $\left.n 2\right]$ are the firstand second-order nonlinear stiffness matrices, respectively; $\left[n 1_{w o}\right]$ is a first-order stiffness matrix due to geometric imperfection. In addition, $\left\{p_{T}\right\}$ and $\left\{p_{r}\right\}$ are thermal and recovery stress load vectors, and $\left\{p_{T w o}\right\}$ and $\left\{p_{r w o}\right\}$ are thermal and recovery stress load vectors due to initial geometric imperfection.

On the other hand, the external virtual work $\delta W_{o r k}$ is given as [18]: 


$$
\begin{aligned}
\delta W_{e x t} & =\int_{A}\left(\delta w\left(-\rho h \frac{\partial^{2} w}{\partial t^{2}}+P_{a}\right)+\delta u\left(-\rho h \frac{\partial^{2} u}{\partial t^{2}}\right)+\delta v\left(-\rho h \frac{\partial^{2} v}{\partial t^{2}}\right)\right) d A \\
& =-\{\delta \theta\}^{T}[m]\{\ddot{\theta}\}-\{\delta \theta\}^{T}[g]\{\dot{\theta}\}-\{\delta \theta\}^{T} \lambda\left[a_{a}\right]\{\theta\}-\{\delta \theta\}^{T} \lambda\left\{p^{\text {sal }}\right\}
\end{aligned}
$$

where $[m],[g]$ and $[a]$ are mass, aerodynamic damping, and aerodynamic influence (stiffness) matrices, respectively. $\left\{p^{s a l}\right\}$ is a static aerodynamic load vector which is function of the initial geometric imperfection $w_{o}$.

By substituting equations (9) and (10) into (8), the governing equations for an imperfect shape memory alloy hybrid composite plate under the combined action of thermal and aerodynamic loads, can be written as:

$$
\begin{aligned}
& {[M]\{\ddot{W}\}+[G]\{\dot{W}\}+\left(\lambda\left[A_{a}\right]+[K]+\left[K_{w o}\right]-\left[K_{T}\right]+\left[K_{r}\right]+\frac{1}{2}\left([N 1]+\left[N 1_{w o}\right]\right)+\frac{1}{3}[N 2]\right)\{W\}} \\
& =\left\{P_{T}\right\}+\left\{P_{T w o}\right\}-\left\{P_{r}\right\}-\left\{P_{r w o}\right\}-\lambda\left\{P^{s a l}\right\}
\end{aligned}
$$

\section{SOLUTION PROCEDURES}

\section{Static Aero-Thermal Deflection}

For the static aero-thermal buckling problem, equation (11) reduces to:

$$
\begin{aligned}
& \left(\lambda\left[A_{a}\right]+[K]+\left[K_{w o}\right]-\left[K_{T}\right]+\left[K_{r}\right]+\frac{1}{2}\left([N 1]+\left[N 1_{w o}\right]\right)+\frac{1}{3}[N 2]\right)\left\{W_{s}\right\} \\
& =\left\{P_{T}\right\}+\left\{P_{T w o}\right\}-\left\{P_{r}\right\}-\left\{P_{r w o}\right\}-\lambda\left\{P^{\text {sal }}\right\}
\end{aligned}
$$

where the subscript "s" stands for static. The solution procedure using NewtonRaphson method is presented in the following.

Introducing the function $\{\Psi(W)\}$ to equation (12), gives

$$
\begin{aligned}
\left\{\Psi\left(W_{s}\right)\right\}= & \left(\lambda\left[A_{a}\right]+[K]+\left[K_{w o}\right]-\left[K_{T}\right]+\left[K_{r}\right]+\frac{1}{2}\left([N 1]+\left[N 1_{w o}\right]\right)+\frac{1}{3}[N 2]\right)\left\{W_{s}\right\} \\
& -\left\{P_{T}\right\}-\left\{P_{T w o}\right\}+\left\{P_{r}\right\}+\left\{P_{r w o}\right\}+\lambda\left\{P^{s a l}\right\}=0
\end{aligned}
$$

Equation (13) can be written in the form of a truncated Taylor series expansion as:

$$
\left\{\Psi\left(W_{s}+\delta W\right)\right\}=\left\{\Psi\left(W_{s}\right)\right\}+\frac{d\left\{\Psi\left(W_{s}\right)\right\}}{d\left(W_{s}\right)}\{\delta W\} \cong 0
$$

where 


$$
\begin{aligned}
\frac{d\left\{\Psi\left(W_{s}\right)\right\}}{d\left(W_{s}\right)} & =\left(\lambda\left[A_{a}\right]+[K]+\left[K_{w o}\right]-\left[K_{T}\right]+\left[K_{r}\right]+[N 1]+\left[N 1_{w o}\right]+[N 2]\right) \\
& =\left[\mathrm{K}_{\tan }\right]
\end{aligned}
$$

Thus, the Newton-Raphson iteration procedure for the determination of the postbuckling deflection can be expressed as follows:

$$
\begin{aligned}
& \left\{\Psi\left(W_{s}\right)\right\}_{i}=\left(\lambda\left[A_{a}\right]+[K]+\left[K_{w o}\right]-\left[K_{T}\right]+\left[K_{r}\right]+\frac{1}{2}\left([N 1]+\left[N 1_{w o}\right]\right)_{i}+\frac{1}{3}([N 2])_{i}\right)\left\{W_{s}\right\}_{i} \\
& \quad-\left\{P_{T}\right\}-\left\{P_{T w o}\right\}+\left\{P_{r}\right\}+\left\{P_{r w o}\right\}+\lambda\left\{P^{s a l}\right\} \\
& {\left[K_{\text {tan }}\right]_{i}\{\delta W\}_{i+1}=-\left\{\Psi\left(W_{s}\right)\right\}_{i}} \\
& \{\delta W\}_{i+1}=-\left[K_{\text {tan }}\right]^{-1}\left\{\Psi\left(W_{s}\right)\right\}_{i} \\
& \left\{W_{s}\right\}_{i+1}=\left\{W_{s}\right\}_{i}+\{\delta W\}_{i+1}
\end{aligned}
$$

Convergence occurs in the above procedure when the maximum value of $\{\delta W\}_{i+1}$ becomes less than a given tolerance $\varepsilon_{t o l}$, i.e. $\max \left|\{\delta W\}_{i+1}\right| \leq \varepsilon_{t o l}$.

\section{Free Vibration of Thermally buckled SMAHC Panels}

From equation (11), the equation of free vibration about a thermally buckled SMAHC plate can be stated as [8]:

$$
[M]\left\{\ddot{W}_{t}\right\}+\left(\lambda\left[A_{a}\right]+[K]+\left[K_{w o}\right]-\left[K_{T}\right]+\left[K_{r}\right]+[N 1]_{s}+\left[N 1_{w o}\right]+[N 2]_{s}\right)\left\{W_{t}\right\}=0
$$

This can be written as:

$$
[M]\left\{\ddot{W}_{t}\right\}+\left[K_{\text {tan }}\right]\left\{W_{t}\right\}=0
$$

where the subscript "t" stands for time-dependent or dynamic. Assuming the solution of the above differential equation to take the following form:

$$
\left\{W_{t}\right\}=\bar{c}\{\Phi\} e^{\Omega t}
$$

Therefore, a generalized eigenvalue problem can be stated as:

$$
\left(\Omega^{2}[M]+\left[K_{\text {tan }}\right]\right)\{\Phi\}=0
$$

Thus, the solution procedure comprises the evaluation of the static thermal deflection and the associated stiffness matrices by following the Newton-Raphson iteration procedure outlined in the preceding section, and then, solving the eigenvalue problem of equation (19) for the natural frequencies $\Omega$ of a thermally buckled SMA hybrid composite plate with initial geometric imperfection. 


\section{NUMERICAL RESULTS AND DISCUSSIONS}

Aero-thermal post-buckling and natural vibration behavior of an imperfect laminated composite plate with and without SMA is studied. Convergence is found to occur at a 6 $x 6$ finite element mesh and thus used. Table (1) presents the material properties of the composite matrix and SMA fiber [19]. Uniform temperature change was applied to the plate, and the reference temperature is assumed to be $21^{\circ} \mathrm{C}$ in this study.

Figure 3 shows the thermal postbuckling equilibrium paths for simply supported, eightlayered symmetric cross ply [0/90/90/0 $]_{s}$ graphite-epoxy laminate with three different aspect ratios and subjected to a uniform temperature distribution. The curves are shown for perfect plate $\left(w_{o}=0\right)$ and also for a plate with an initial geometric imperfection of 0.1 times the plate thickness $h$. The length of the plate $a$ is kept constant and $a / h=250$. The temperatures have been normalized by $T_{c r}$, the buckling temperature of a square laminate. It is seen that increasing the plate aspect ratio, results in increasing the critical buckling temperatures, and may also results in a more pronounced difference between the perfect plate response and the imperfect one. Moreover, due to the presence of the initial imperfection, bifurcation buckling does not take place. Because any small temperature rise results in a prompt transverse deflection of the imperfect panel. To validate the present formulation, the results presented in Figure 3 were compared to those of Figure 6 in Ref. [11] and were found to be in a good agreement.

The plate dimensions and stacking sequence adopted hereinafter are $0.381 \times 0.305 \times$ $0.0013(\mathrm{~m})$ and $[0 /-45 / 45 / 90]_{s}$. Figures 4 and 5 demonstrate the effectiveness of using Nitinol SMA fibers at certain pre-strain value and different volume fractions in delaying the bucking temperature, and suppressing the postbuckling deflection for both clamped and simply supported SMAHC plates. Generally speaking, increasing the volume fraction of SMA improves the thermal stability of SMAHC plates of different boundary conditions. It is also seen that, an initial imperfection 0.1 times the plate thickness $h$ has no noticeable effect on the panel response.

Figure 6 shows the gradual evolution of the aerostatic deflection shape of a buckled, simply supported SMAHC plate panel with 5\% SMA volume fraction, $1 \%$ pre-strain and a temperature rise of $34{ }^{\circ} \mathrm{C}$. It is seen that the maximum panel's peak amplitude is gradually swept back in the flow direction with less static deflection as the nondimensional dynamic pressure $\lambda$ is increased. It is also seen that the difference between the perfect and imperfect plate responses increases with increasing $\lambda$, i.e. the initial imperfection decreases the aerodynamic stiffening effect added to the panel as $\lambda$ increases.

Figure 7 presents the fundamental frequency behavior of a SMAHC plate with SMA volume fraction $5 \%$ and different pre-strain values. It is seen that the fundamental frequencies decrease between room temperature $\left(T_{\text {ref }}\right)$ and the critical buckling temperature $\left(T_{c r}\right)$ due to the thermal expansion effect. At $T_{c r}$, the fundamental frequency drops to zero as the plate stiffness drops to zero at the buckling point. The frequencies increase after passing $T_{\text {cr }}$ because geometrical nonlinearity adds stiffness to the plate. For the $1 \%$ pre-strain curve, it is seen that there are three null frequencies at three temperature values at which the three deflection bifurcations occur, see Figure 5 . In the postbuckling region, the fundamental frequencies of the SMAHC panels have shown a 
decrease in value, which is due to the increase in mass offered by SMA fibers as well as the decrease in the stiffness compared with the highly deflected plate without SMA. For the clamped panel presented in Figure 8 , the frequencies related to $5 \%$ volume fraction show a non-monotonic decrease in the pre-buckling region, due to the nonmonotonic rate of increase of the recovery stresses in this temperature range. For the $10 \%$ and $15 \%$ volume fractions curves, it is seen that the fundamental frequency starts first to increase as the recovery stresses dominate thermal expansion effect. After certain temperature rise, the SMA recovery stresses ceases to fully compensate the reduced stiffness due to thermal expansion resulting in a decrease in the natural frequencies until reaching null values at the buckling bifurcation point. From these curves it may be observed that the presence of a small imperfection in the plate may be favorable from the dynamic point view through preventing the plate from having very low or null fundamental frequencies at the vicinity of the critical buckling temperature.

\section{CONCLUSIONS}

In this work, a new nonlinear finite element model is presented for the aero-thermal buckling and free vibration response of an imperfect shape memory alloy hybrid composite panels under combined thermal and aerodynamic loads. The nonlinear governing equations for a thin, imperfect rectangular plate are obtained using Marguerre curved plate theory, von Karman strain-displacement relations, and the principle of virtual work. The nonlinear temperature dependence of material properties for the composite matrix and SMA fibers is considered in the formulation. The NewtonRaphson iteration method is employed to obtain the nonlinear deflections, while an Eigen value problem is solved at each temperature rise to predict the free vibration frequencies about the deflected equilibrium position. Results showed that SMA fiber embeddings can be very useful in thermal buckling through increasing the buckling temperature and decreasing or suppressing the thermal postbuckling deflections. Moreover, it is found that increasing the plate aspect ratio may results in a more pronounced effect of the initial geometric imperfection. From the free vibration results it may be observed that the presence of a small geometric imperfection may be favorable from the dynamic point view through preventing the plate from having very low or null fundamental frequencies at the vicinity of the critical buckling temperatures.

\section{REFERENCES}

[1] Tauchart, T.R., "Thermally Induced Flexure, Buckling, and Vibration of Plates", Appl. Mech. Rev., Vol. 44, No. 8, pp. 347-360, (1991).

[2] Thornton, E.A., "Thermal Buckling of Plates and Shells", Appl. Mech. Rev., Vol. 46, No. 10, pp. 485-506, (1993).

[3] Gray, C.C., and Mei, C., "Finite Element Analysis of Thermal Postbuckling and Vibrations of Thermally Buckled Composite Plates," $32^{\text {nd }}$ AIAA/ASME/ASCE/ AHS/ASC Structures, Structural Dynamics, and Materials Conference, Pt. 4, AIAA, Washington, DC, pp. 2996-3007, (1991).

[4] Jones, R. and Mazumdar, J., "Vibration And Buckling Of Plates At Elevated Temperatures", J. Solid Structures, Vol.16, pp. 61-70, (1980).

[5] Shi, Y., Lee, R.Y. and Mei, C., "Coexiting Thermal Post-Buckling Of Composite Plates With Initial Imperfections Using Finite Element Modal Method", J. Thermal Stresses, Vol. 22, pp. 595-614, (1999). 
[6] Ibrahim, H. H., Tawfik, M., and Al-Ajmi, M., "Aero-Thermo-Mechanical Characteristics of Functionally Graded Material Panels with TemperatureDependent Material Properties," Eighth International Congress of Fluid Dynamics and Propulsion (ICFDP 8), American Society of Mechanical Engineers Paper ICFDP-EG-116,Dec. 2006.

[7] Ibrahim, H.H., Tawfik, M., and Al-Ajmi, M., "Non-Linear Panel Flutter for Temperature-Dependent Functionally Graded Material Panels", Computational Mechanics, Vol. 41, No. 2, pp. 325-334, (2007).

[8] Ibrahim, H.H., Tawfik, M., and Al-Ajmi, M., "Thermal Buckling and Nonlinear Flutter Behavior of Functionally Graded Material Panels," Journal of Aircraft, Vol. 44, No. 5, pp. 1610-1618, (2008).

[9] Shi, Y., Lee, R.Y., and Mei, C., "Thermal Post Buckling of Composite Plates Using the Finite Element Modal Coordinate Method", J. of Thermal Stresses, Vol. 22, No. 6, pp. 595-614, (1999).

[10] Hui-Shen Shen, "Thermal Postbuckling Behavior of Shear Deformable FGM Plates with Temperature-Dependent Properties", Computer Methods in Applied Mechanics and Engineering, Vol. 190, pp. 5377-5390, (2001).

[11] Girish, J., and Ramachandra, L.S., "Thermal Postbuckling Vibrations of Symmetrically Laminated Composite Plates with Initial Geometric Imperfections", J. of Sound and Vibration, Vol. 282, pp. 1137-1153, (2005).

[12] Shariat, B.A., and Eslami, M.R., "Thermal Buckling of Imperfect Functionally Graded Plates", Solids and Structures, Vol. 43, pp. 4082-4096, (2006).

[13] Mirzavand, B., and Eslami, M. R., "Thermal Buckling of Imperfect Functionally Graded Cylindrical Shells Based on the Wan-Donnell Model", J. of Thermal Stresses, Vol. 29, pp. 37-55, (2006).

[14] Hui-Shen Shen, "Thermal Postbuckling Behavior of Shear Deformable FGM Plates with Temperature-Dependent Properties", Int. J. of Mechanical Sciences, Vol. 49, pp. 466-478, (2007).

[15] Cross, W.B., Kariotis, A.H. and Stimeler, F.J., "Nitinol Characterization Study", NASA CR-14B, (1969).

[16] Birman, V., "Review Of Mechanics Of Shape Memory Alloy Structures", Appl. Mech. Rev., Vol. 50, pp. 629-645, (1997).

[17] Tawfik, M., Ro, J.J. and Mei, C., "Thermal Post-Buckling and Aeroelastic Behavior of Shape Memory Alloy Reinforced Plates", Smart Materials and Structures, Vol. 11, 297-307, (2002).

[18] Park, J.S., Kim, J.H. and Moon, S.H., "Vibration of Thermally Post-Buckled Composite Plates Embedded With Shape Memory Alloy Fibers", Composite Structures, Vol. 63, pp. 179-188, (2004).

[19] Ibrahim, H. H., Tawfik, M., and Negm, H. M., "Thermal Postbuckling and Flutter Behavior of Shape Memory Alloy Hybrid Composite Plates," Eighth International Congress of Fluid Dynamics and Propulsion (ICFDP 8), American Society of Mechanical Engineers Paper ICFDP-EG-153, Dec. 2006.

[20] Ibrahim, H.H., Tawfik, M., and Negm, H.M., "Thermoacoustic Random Response of Shape Memory Alloy Hybrid Composite Plates," Journal of Aircraft, in press, DOI: $10.2514 / 1.32843$.

[21] Azzouz, M.S., "Nonlinear Flutter of Curved Panels Under Yawed Supersonic Flow Using Finite Elements", PhD Dissertation, Old Dominion University, Mechanical Engineering Department, Norfolk, Virginia, (2005).

[22] Reddy, J.N., Theory and Analysis of Elastic Plates, Taylor \&Francis, (1999). 
Table 1 Material properties of composite matrix and SMA fiber

\begin{tabular}{lll}
\hline \multicolumn{1}{c}{ Nitinol } & \multicolumn{1}{c}{ Graphite-epoxy } \\
\hline See Figs. 1 and 2 for Young's & E1 & $155\left(1-6.35 \times 10^{-4} \Delta \mathrm{T}\right) \mathrm{GPa}$ \\
modulus and recovery stresses. & E2 & $8.07\left(1-7.69 \times 10^{-4} \Delta \mathrm{T}\right) \mathrm{GPa}$ \\
$\mathbf{G} 25.6 \mathrm{GPa}$ & $\mathbf{G 1 2}$ & $4.55\left(1-1.09 \times 10^{-3} \Delta \mathrm{T}\right) \mathrm{GPa}$ \\
$\boldsymbol{\rho} 6450 \mathrm{~kg} / \mathrm{m}^{3}$ & $\boldsymbol{\rho}$ & $1550 \mathrm{Kg} / \mathrm{m}^{3}$ \\
$\mathbf{v} 0.3$ & $\mathbf{v}$ & 0.22 \\
$\boldsymbol{\alpha} 10.26 \times 10^{-6} /{ }^{\circ} \mathrm{C}$ & $\alpha 1$ & $-0.07 \times 10^{-6}\left(1-0.69 \times 10^{-3} \Delta \mathrm{T}\right) /{ }^{\circ} \mathrm{C}$ \\
& $\alpha 2$ & $30.6 \times 10^{-6}\left(1+0.28 \times 10^{-4} \Delta \mathrm{T}\right) /{ }^{\circ} \mathrm{C}$ \\
\hline
\end{tabular}
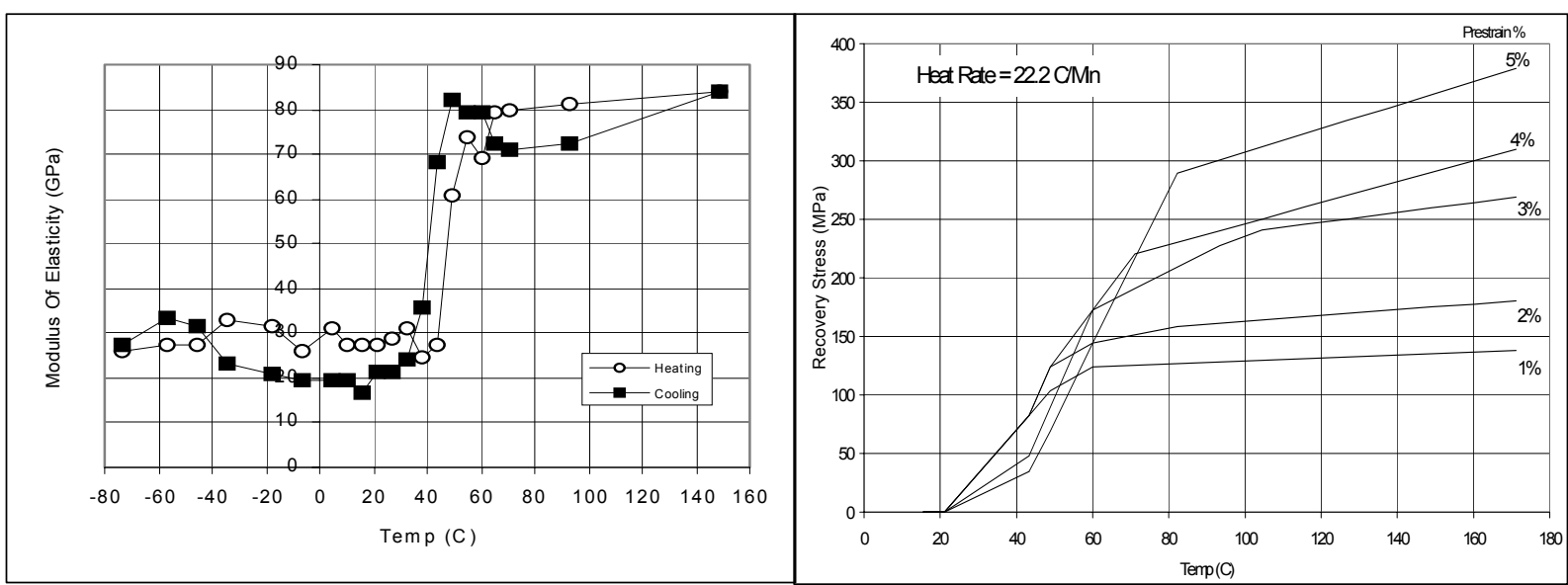

Fig. 1. Variation of modulus of elasticity recovery stresses with temperature

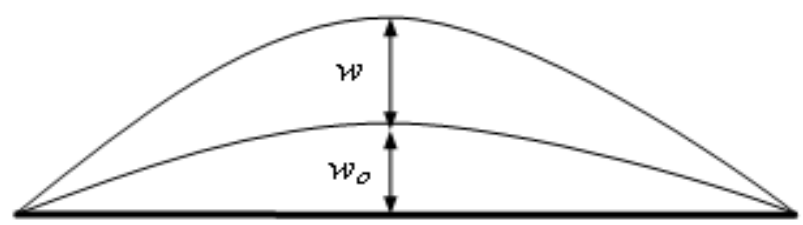

Fig. 2. Displacement distribution sketch 


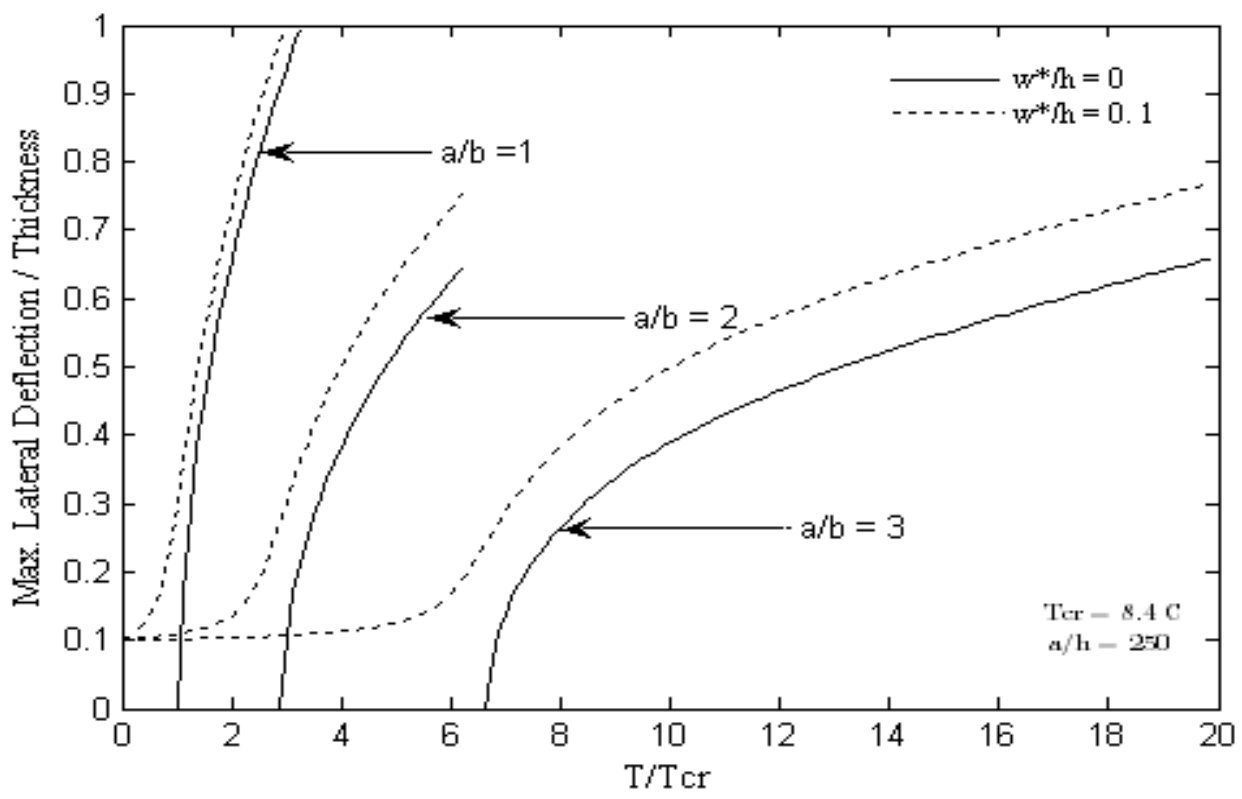

Fig. 3. Postbuckling deflection curves for different aspect ratios $(a / b)$ of the laminated plate $(0 / 90 / 90 / 0)_{\mathrm{s}}$

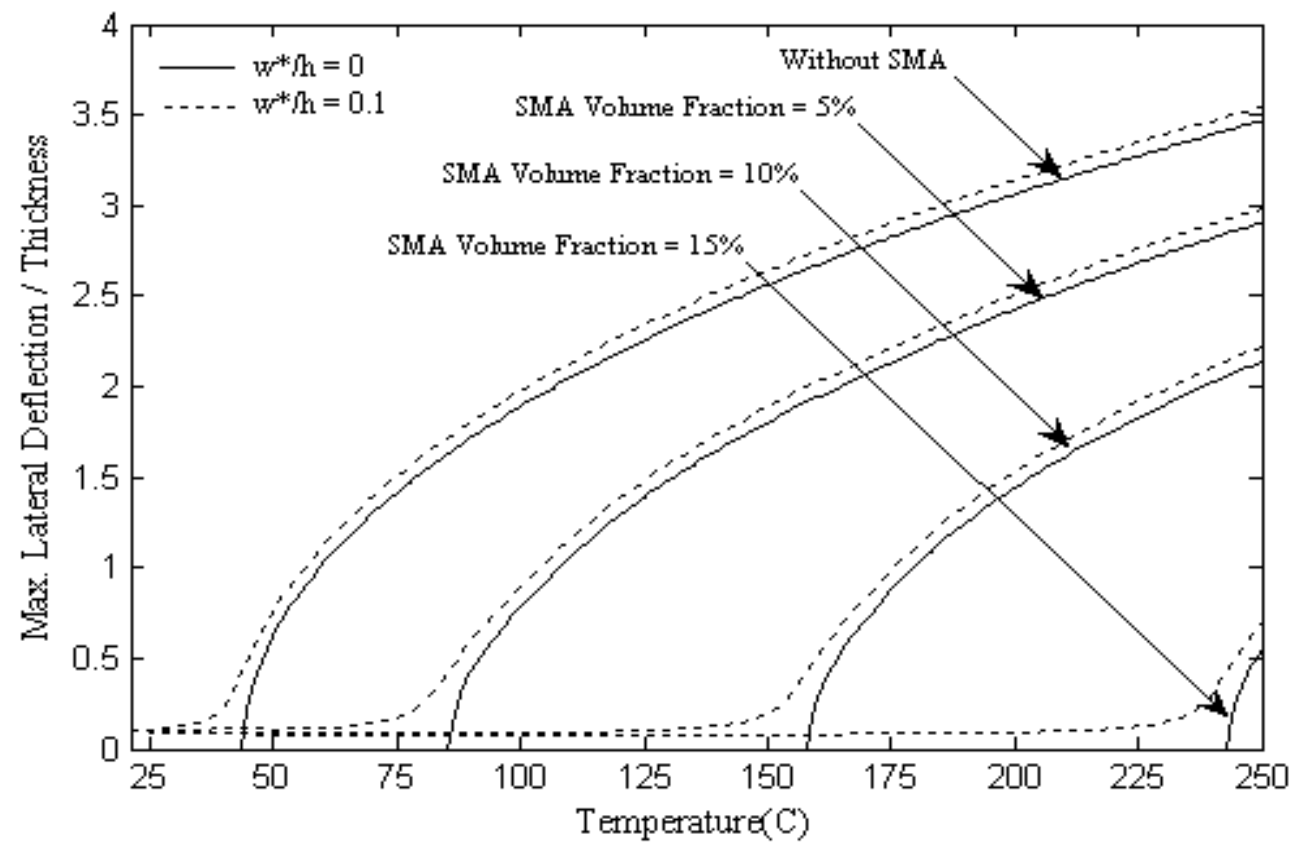

Fig. 4. Postbuckling deflection curves for a clamped SMAHC plate with $3 \%$ pre-strain and different volume fractions 


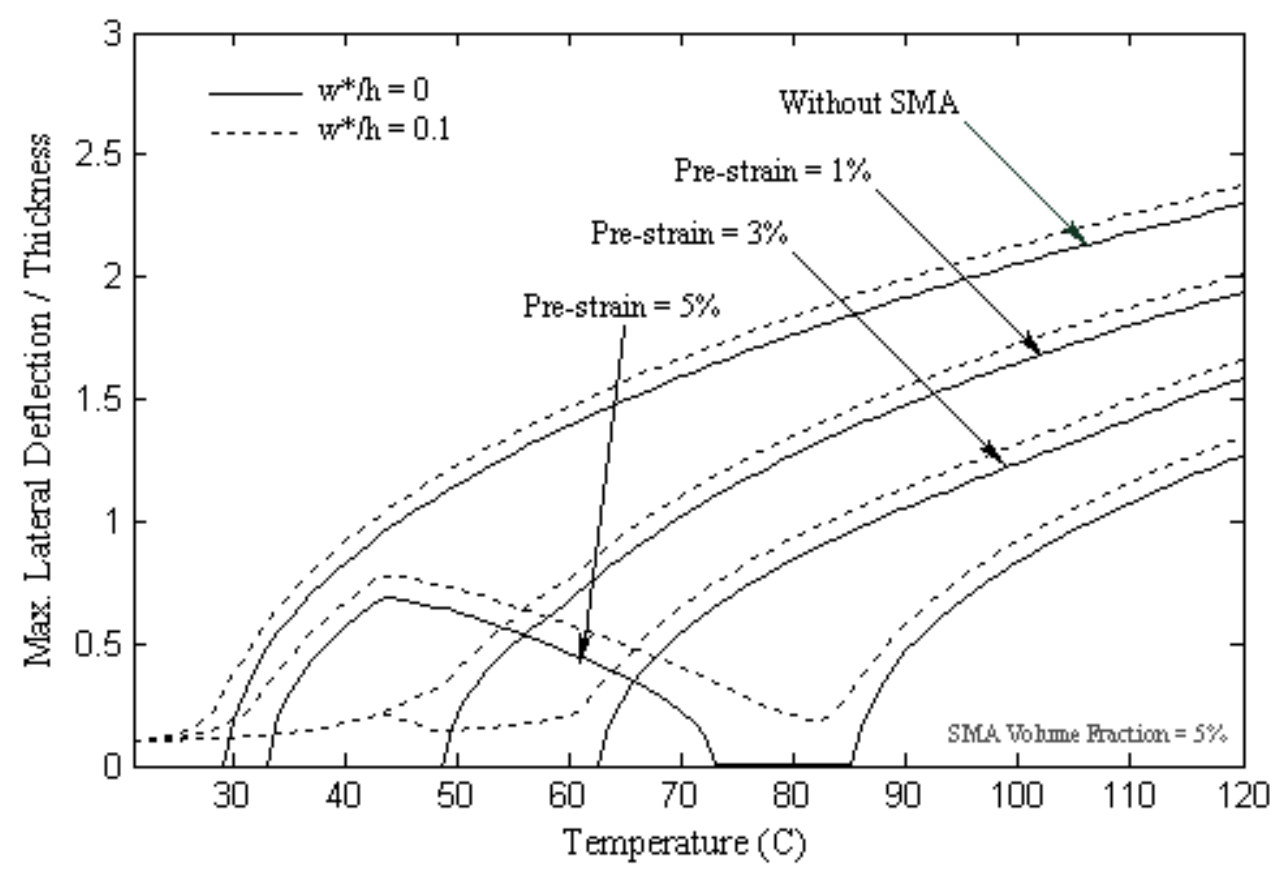

Fig. 5. Post buckling deflection curves for a simply supported SMAHC plate with 5\% volume fraction and different pre-strains

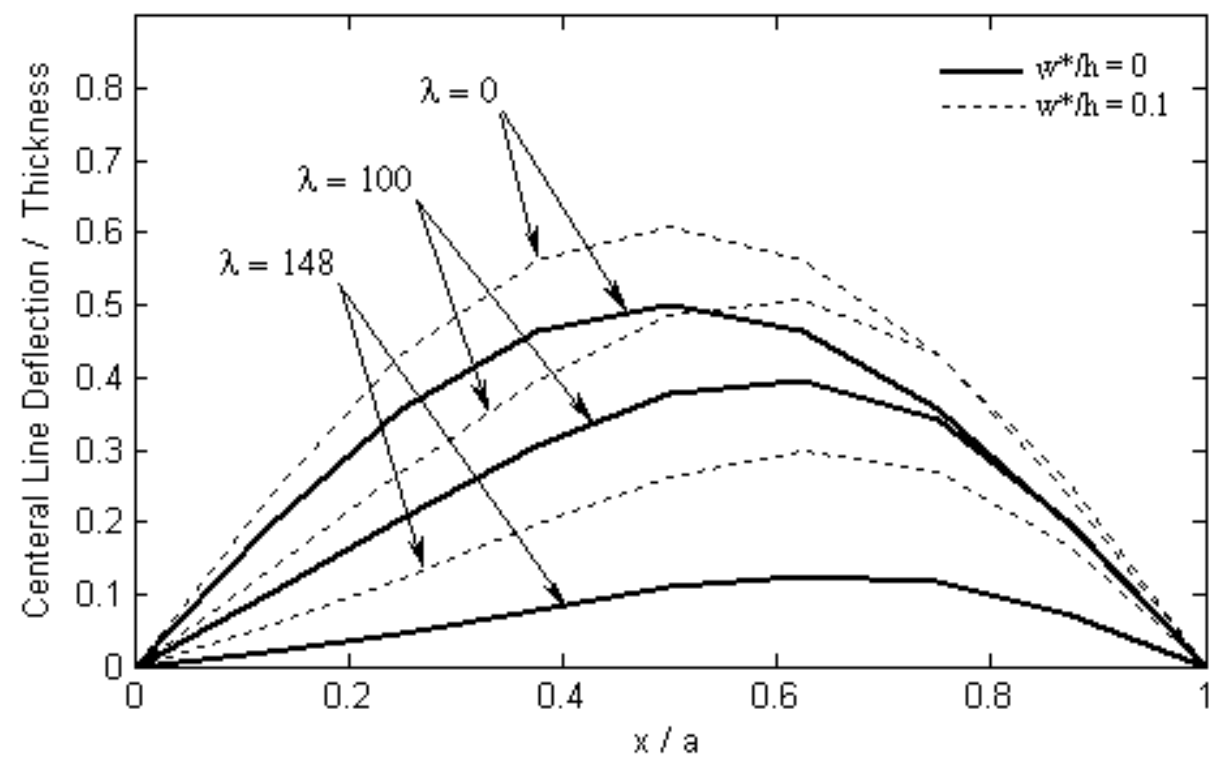

Fig. 6. Central line deflection curves for a simply supported SMAHC plate at different non-dimensional dynamic pressure $\lambda$ and temperature rise $34{ }^{\circ} \mathrm{C}$ 


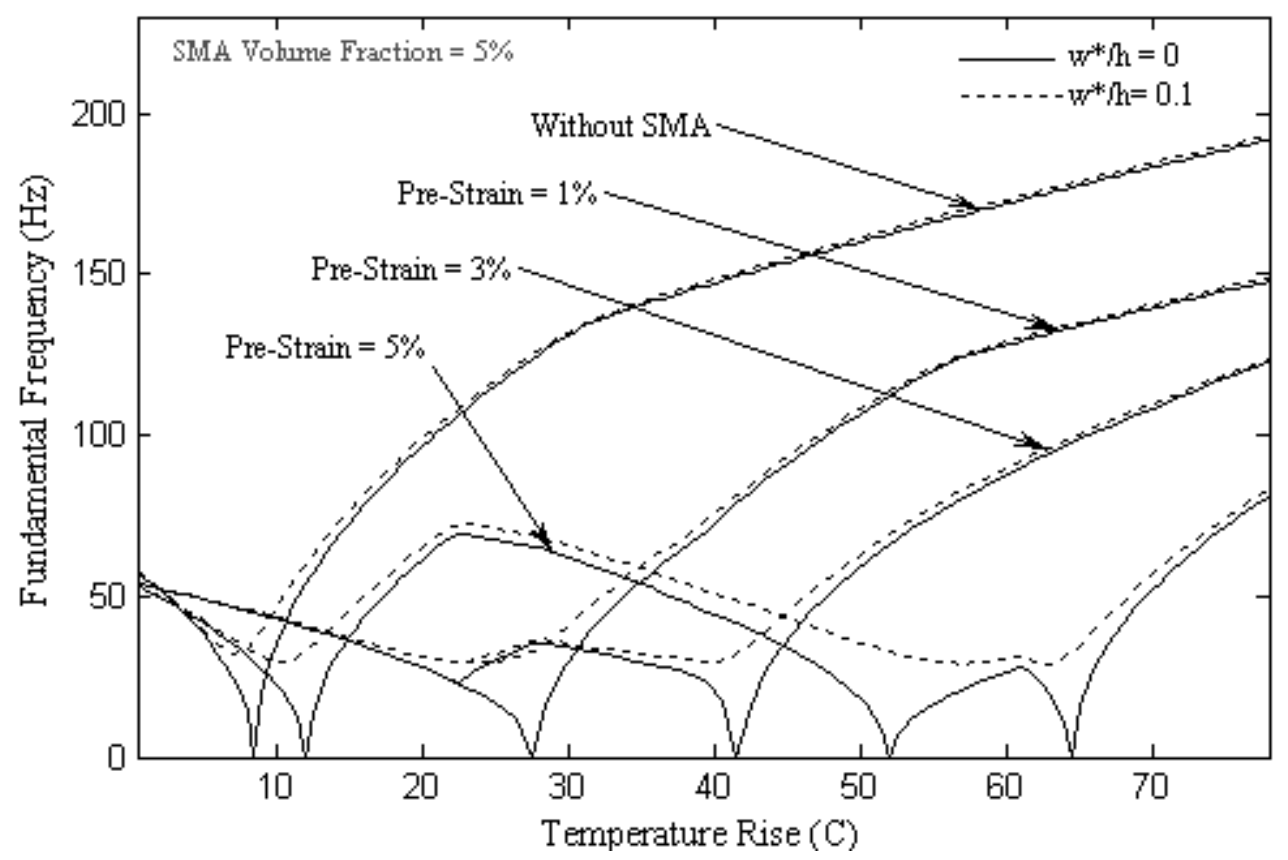

Fig. 7. Fundamental frequencies of simply supported SMAHC plates with $5 \%$ volume fraction and different pre-strain values

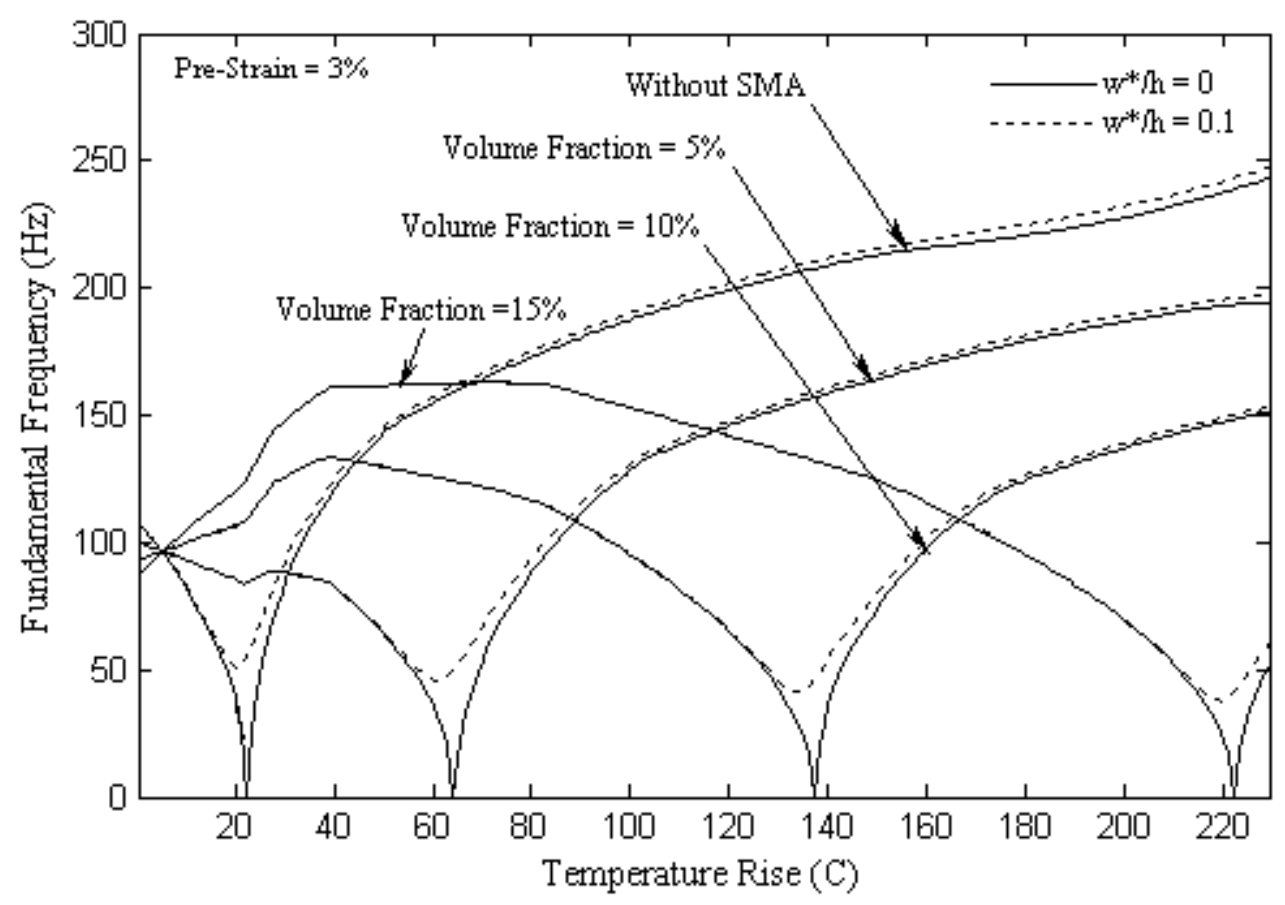

Fig. 8. Fundamental frequencies of clamped SMAHC plates with $3 \%$ pre-strain and different volume fraction values 